Lily Chang MD FRCPC, Lian Looi-Lyons MD FRCPC, * Lydia Bartosik MD FRCPC, Simon Tindal MB CHB FFARCS FRCPC

\section{Anesthesia for cesarean section in two patients with brain tumours}

Purpose: To describe two patients with brain tumours where general anesthesia was used for cesarean sections under emergency and urgent conditions.

Clinical features (case \#1): The first patient presented at 38 wk gestation with an acute intracranial tumour herniation, requiring emergency craniotomy and simultaneous cesarean section. General anesthesia was induced with thiopental and vecuronium, maintained with enflurane $1 \%$ in $\mathrm{O}_{2} 100 \%$. Maternal $\mathrm{P}_{\mathrm{ET}} \mathrm{CO}_{2}$ was maintained at 25 $\mathrm{mmHg}$. After delivering a healthy infant, she was given syntocinon, mannitol and dexamethasone $\mathrm{i}$; anesthesia was maintained with fentanyl, nitrous oxide $50 \%$ in $\mathrm{O}_{2}$ and isoflurane $1 \%$ during frontal-lobe tumour resection.

Clinical features (case \#2): The second patient presented at 37 wk gestation for urgent cesarean section because of placental insufficiency. She had had a brain tumour resection four years earlier. An increase in intracranial pressure necessitated craniotomy for decompression at 20 wk gestation. She was further treated with dexamethasone, carbamazepine and radiation for control of cerebral oedema at 34 wk. Cesarean section was performed under general anesthesia; rapid-sequence- induction with thiopental and succinylcholine, followed by isofurane $1 \%$ in $\mathrm{O}_{2} 100 \%$. Syntocinon, fentanyl and atracurium iv were administered after delivery of a healthy infant. Although neurosurgeons stood by, their intervention was unnecessary.

Conclusion: General anesthesia remains safe and dependable for operative delivery in parturients with intracranial tumour. Tracheal intubation allows maternal hyperventilation thereby controlling raised intracranial pressure. Hemodynamic stability is readily achieved to maintain cerebral perfusion. However, a multidisciplinary-team approach is critical for successful patient management.

Objectif : Décrire deux patientes souffrant de tumeur cérébrale pour lesquelles on a utilisé l'anesthésie générale lors d'une césarienne dans des conditions imprévues et urgentes.

Aspects cliniques ( $1^{\circ}$ cas) : La première patiente s'est présentée à 38 semaines de gestation souffrant d'une hernie tumorale intracrânienne aiguë exigeant simultanément une craniotomie et une césarienne d'urgence. L'anesthésie générale, induite avec du thiopental et du vécuronium, a été maintenue avec $1 \%$ d'enflurane dans $100 \%$ d' $\mathrm{O}_{2}$ et la $\mathrm{P}_{\mathrm{ET}} \mathrm{CO}_{2}$ maternelle, maintenue à $25 \mathrm{mmHg}$. Après la naissance d'un bébé en santé, la mère a reçu du syntocinon, du mannitol et de la dexaméthasone iv ; on a maintenu l'anesthésie avec du fentanyl, un mélange de protoxyde d'azote et d' $\mathrm{O}_{2}$ à $50 \%$ et de l'isoflurane $1 \%$ pendant la résection de la tumeur du lobe frontal.

Aspects cliniques ( $\left.2^{\circ} \mathrm{cas}\right)$ : La seconde patiente s'est présentée à 37 semaines pour subir une césarienne d'urgence rendue nécessaire par une insuffisance placentaire. Quatre ans avant, elle avait subi la résection d'une tumeur cérébrale, à 20 semaines, une craniotomie pour contrer l' augmentation de la pression intracrânienne et, enfin, à 34 semaines, on a contrôlé l'œdème cérébral avec de la dexaméthasone, de la carbamazépine et de la radiothérapie. La césarienne a eu lieu sous anesthésie générale avec du thiopental et de la succinylcholine, pour l'induction à séquence rapide, et de l'isoflurane $1 \%$ dans $100 \% \mathrm{~d}^{\prime} \mathrm{O}_{2}$. Du syntocinon, du fentanyl et de l'atracurium iv ont été administrés après la naissance d'un enfant en santé. Les neurochirurgiens, restés sur place, n'ont pas eu à intervenir.

Conclusion : L'anesthésie générale reste sûre et fiable lors de césariennes chez des parturientes souffrant de tumeur intracrânienne. L'intubation endotrachéale permet l'hyperventilation de la mère et, donc, le contrôle de la pression intracrânienne. La stabilité hémodynamique est rapidement assurée afin de maintenir la perfusion cérébrale. Cependant, l'action d'une équipe multidisciplinaire est cruciale pour que le traitement réussisse.

From the Departments of Anaesthesia, St. Michael's Hospital, Wellesley Central site, 160 Wellesley Street East, Toronto, Ontario M4Y 1J3, Canada and The Toronto Hospital, General Division, ${ }^{*}$ Toronto, Ontario, Canada.

Address correspondence to: Dr. Lily Chang, 195 St. Patrick Street, Apt. 906B, Toronto, Ontario M5T 2 Y8 Phone: 416-593-0470; Fax: 416-593-6503; E-mail: Lian_Lyons@hotmail.com

Accepted for publication October 22, 1998 
M ANAGEMENT of parturients with brain tumours involves complex medical issues, and is a challenge to anesthesiologist, obstetrician and neurosurgeon. Details of the anesthetic management in these patients are seldom reported. Obstetrical and neuroanesthetic considerations for maternal safety and fetal well being may be conflicting. To date, only a few case reports on use of regional anesthesia for labour and delivery of parturients with brain tumours have been published. ${ }^{1,2,3}$ We present two cases where general anesthesia was used for cesarean section (CS) in patients with brain tumour.

\section{Case reports}

\section{Patient \#I}

A 29 -yr old primigravida (height $150 \mathrm{~cm}$, weight 60 $\mathrm{kg}$ ) at $38 \mathrm{wk}$ gestation, presented with sudden onset of seizures. Her medical history was unremarkable except for migraine headaches and an asymptomatic mitral valve prolapse. Her antenatal history included complaints of nausea and vomiting, headaches, forgetfulness and irrational behaviour a few weeks before admission, and these symptoms had been attributed to her pregnancy.

While being investigated in the community hospital, the patient's trachea was intubated because of rapid deterioration of her mental state. An emergency computed tomography (CT) scan showed a large mass in the left frontal lobe with midline shift. On arrival in our hospital, her pupils were fixed and dilated, and her corneal and gag reflexes were absent. Bilateral decerebrate posturing was noted. She had a Glasgow Coma Scale (GCS) score of 4 . It was felt that catastrophic brain stem herniation was occurring and that the best option for maternal and fetal survival would be an emergency craniotomy with frontal lobe decompression and a simultaneous CS.

The patient was transferred directly to the operating room within ten minutes of her arrival in the emergency room. Standard monitors - ECG, noninvasive $\mathrm{BP}$, pulse oximeter and a radial arterial line were applied. Left lateral tilt was used to prevent aortocaval compression. General anesthesia was induced with $250 \mathrm{mg}$ thiopental and $5 \mathrm{mg}$ vecuronium. Maternal BP was $180 \mathrm{mmHg}$ systolic, with a heart rate of $100 \mathrm{bpm}$ before induction. These decreased to and remained at $140-150 \mathrm{mmHg}$ systolic and $80-90$ bpm throughout the procedure. Anesthesia was continued with enflurane $1 \%$ in oxygen $\left(\mathrm{O}_{2}\right) 100 \%$. Maternal $\mathrm{P}_{\mathrm{ET}} \mathrm{CO}_{2}$ was maintained at $25 \mathrm{mmHg}$. A healthy male infant, weighing $2.95 \mathrm{~kg}$, was delivered $14 \mathrm{~min}$ after induction of anesthesia.. His Apgar scores were 7 at 1 minute and 9 at 5 minutes. After the infant's delivery, $5 \mathrm{u}$ syntocinon $i v$, followed by an infusion of $20 \mathrm{u} \cdot \mathrm{L}^{-1}$ Ringer's lactate, $10 \mathrm{mg}$ dexamethasone ip bolus and $40 \mathrm{mg}$ mannitol ip infusion were administered to the mother. Maintenance of anesthesia was supplemented with $100 \mu \mathrm{g}$ fentanyl iv and inhalational agents were switched to isoflurane $1 \%$ in nitrous oxide $\left(\mathrm{N}_{2} \mathrm{O}\right) 50 \%$ and $\mathrm{O}_{2}$.

Surgical management involved a two-team approach. Craniotomy and CS were commenced simultaneously; the dura was opened at the time of delivery of the baby. The left hemisphere was noted to be herniating through the dural opening. After delivery of the infant and confirmation of the pathology of a highly cellular undifferentiated (grade IV) glioblastoma multiforme, the neurosurgeons proceeded to perform a frontal lobectomy.

Postoperatively, the patient was transferred to the neurosurgical intensive care unit. Her trachea was extubated the next day. However, on postoperative day 3 , she became very drowsy. Her GCS score deteriorated from 15 to 10 within three hours. A repeat CT scan showed a recurrence of the intracranial midline shift, and the patient underwent repeat craniotomy for radical excision of the tumour. At the end of the procedure, the neuromuscular blockade was reversed and an awake extubation performed in the operating room.

The remainder of the postoperative course was uneventful; she was discharged home nine days later. Arrangements were made for urgent assessment by a radiation oncologist. Her prognosis was considered to be extremely poor.

\section{Patient \#2}

A 28 -yr old primigravida (height $165-\mathrm{cm}$, weight 83 $\mathrm{kg}$ ) was referred at 37 wk gestation for urgent CS because of placental dysfunction, intrauterine growth retardation and oligohydramnios. Her medical history included a brain tumour (astrocytoma) resection four years before admission. The present pregnancy was eventful. At 20 wk gestation, the brain tumour recurred and a craniotomy was performed for intracranial decompression. At $34 \mathrm{wk}$, worsening cerebral oedema necessitated treatment with radiation, dexamethasone and carbamazepine. At $36 \mathrm{wk}$, a series of magnetic resonance imaging (MRI) scans showed a slight increase in cerebral edema, with a mild right-toleft frontal shift. At $37 \mathrm{wk}$ gestation, she was admitted for urgent CS because of placental dysfunction.

On physical examination, the patient was alert, with a GCS of 15. There was no evidence of any neurological deficit or papilloedema. After consultation among patient, obstetrician, anesthesiologist and neurosur- 
geon, it was decided that the baby be delivered operatively under general anesthesia, with the neurosurgeon standing by in the operating room in case neurosurgical intervention became necessary.

Preoperatively, the patient was given $30 \mathrm{ml} 0.3 \mathrm{~mol}$ sodium citrate and her usual medications ( $4 \mathrm{mg}$ dexamethasone and $200 \mathrm{mg}$ carbamazepine) po. In the operating room, she was placed in a $15^{\circ}$ head-up position with a left lateral tilt. Standard monitors and a radial arterial line were applied before induction of anesthesia. The patient's trachea was intubated after rapid sequence induction with $450 \mathrm{mg}$ thiopental and $100 \mathrm{mg}$ succinylcholine. Anesthesia was continued with isoflurane $1 \%$ in $\mathrm{O}_{2} 100 \%$. Ventilation was maintained at a $\mathrm{P}_{\mathrm{ET}} \mathrm{CO}_{2}$ of $21 \mathrm{mmHg}$. Before induction of anesthesia $B P$ was $140 / 90 \mathrm{mmHg}$ with a heart rate of $90 \mathrm{bpm}$ and, after induction, they decreased to and were maintained at $90-110 \mathrm{mmHg}$ systolic and 80 $\mathrm{bpm}$, respectively, throughout the procedure.

A healthy male infant weighing $2.28 \mathrm{~kg}$ was delivered, seven minutes after skin incision. His Apgar score at one minute was 8 ; at five minutes, 9. After delivery, anesthesia was maintained with isoflurane $0.75 \%$ in $\mathrm{O}_{2} 100 \%$, supplemented with $100 \mu \mathrm{g}$ fentanyl and $20 \mathrm{mg}$ atracurium $i v$. Syntocinon 5 unit bolus and an $i v$ infusion of $20 \mathrm{u} \cdot \mathrm{L}^{-1}$ Ringer's lactate were also administered. There was no indication for neurosurgical intervention.

At the end of the surgery, the patient was awake and the trachea was extubated in the operating room,. Her postoperative course was uneventful; she was discharged home four days later.

\section{Discussion}

The incidence of brain tumour in the female population is estimated to be 6 per 100,000 (1998 Statistics Canada estimate). The incidence is not known to be increased in pregnant women although some of these tumours tend to become larger and show accelerated growth during pregnancy due to fluid retention, increased blood volume or pregnancy hormones. ${ }^{5}$ Symptoms of increased intracranial pressure (ICP) may be misinterpreted as normal occurrences in pregnancy: Nausea and vomiting are normal in early pregnancy; headaches, visual disturbances and convulsions may be attributed to toxemia of pregnancy. This may delay the diagnosis of intracranial tumour in pregnant women, as in patient \#1.

Patient \#1 was unique because she presented suddenly at term pregnancy with an acute herniating brain tumour requiring emergency craniotomy and simultaneous CS. She showed signs of coning and rapid deterioration. General anesthesia was the tech- nique of choice. Cerebral perfusion pressure is achieved by maintaining maternal BP at 140-150 $\mathrm{mmHg}$ systolic and controlling the elevated ICP by hyperventilation. Maternal hypocarbia was maintained at $25 \mathrm{mmHg}$ for $14 \mathrm{~min}$ before delivery of the infant. This did not result in neonatal depression. Oxygen $100 \%$ was initially administered because it results in higher umbilical venous $\mathrm{O}_{2}$ saturation and higher Apgar scores than does $\mathrm{O}_{2} 50 \%$ in $\mathrm{N}_{2} \mathrm{O}$. Nitrous oxide was avoided because it may worsen cerebral vasodilation, especially when used with a potent inhalational agent. ${ }^{7}$ It may cause cerebral stimulation and increase in cerebral oxygen metabolic rate $\left(\mathrm{CMRO}_{2}\right)^{8}$

Isoflurane, halothane, enflurane, ${ }^{9}$ desflurane ${ }^{10}$ and sevoflurane ${ }^{11}$ have been used safely during $C S$, without harmful effects to the fetus. Isoflurane is favoured in neuroanesthesia because it reduces $\mathrm{CMRO}_{2}$ more than do halothane or enflurane, and because cerebral ischemia is better tolerated. ${ }^{13}$ In patient \#l, isoflurane could also have been used initially instead of enflurane, thus avoiding the change from one inhalation agent to another.

The use of oxcytocic drugs in patients with intracranial tumour, or of drugs to control ICP in parturients has not been fully investigated. Oxytocic drugs, such as ergotamine and prostaglandin, have been associated with hypertensive responses, which may aggravate a raised ICP. Syntocinon, a synthetic oxytocin, is the drug of choice. It has been used in patients with intracranial tumours without any adverse effect. ${ }^{2,14}$ Mannitol, is routinely used in patients with brain tumours to decrease brain bulk and ICP. It has been shown to cause fetal hypovolemia and electrolyte imbalance in animal study. However, infusion of mannitol has been used safely in pregnant women. ${ }^{16}$ Dexamethasone is used to decrease cerebral edema. Its acute use may be safe for the fetus; chronic use, however, may result in systolic hypertension, cardiomyopathy, glycosuria, and weight loss in very low-birth weight infants. ${ }^{17}$ Opioids may cause neonatal depression; when used, a neonatologist must be readily available for possible neonatal resuscitation with naloxone.

Syntocinon was administered without adverse effect. Opioids, mannitol and dexamethasone were given after the delivery of the infant, to avoid any potential neonatal problems.

Patient \#2 was referred for urgent CS. Unlike the emergency situation described, there was time for preoperative obstetric, anesthetic, and neurosurgical consultation. She had no signs of increased ICP, and only MRI evidence of cerebral edema. Regional anesthesia for $\mathrm{CS}$ in this patient was considered, but there are few reports of its use. After consultations with the patient, obstetrician, anesthesiologist and neurosurgeon, it was 
decided to proceed with general anesthesia, with the neurosurgeon on stand-by. Rapid-sequence induction is routinely used in obstetrical anesthesia, to reduce the risk of maternal aspiration. Its use was controversial in patient \#2, as a smooth, slow, gentle induction is recommended in patients with increased ICP. Maternal systolic $\mathrm{BP}$ of $90-110 \mathrm{mmHg}$ and maternal $\mathrm{P}_{\mathrm{ET}} \mathrm{CO}_{2}$ of $21 \mathrm{mmHg}$ for seven minutes did not result in any adverse effect on the newborn. Maternal hypocarbia and alkalosis may result in umbilical vasoconstriction and a shift of oxygen hemoglobin dissociation curve to the left, both of which may potentially have deleterious effects on the fetus.

The choice of anesthetic technique for CS in a parturient with a coexisting brain tumour depends upon various factors, such as the type and location of the tumour, the neurological condition of the mother, her own preference, the status of the fetus, and the urgency of the surgery. Early neurosurgical consultation is advised, to determine whether the tumour should be managed conservatively or surgically and, if the latter, whether the surgery shall be before or after delivery of the fetus. Assessment of the mother must include evaluation of the presence or absence of raised ICP, NPO status, the anticipated difficulty of managing her airway, and the parient's preference for the type of anesthetic technique. Assessment of the fetus must include the maturity of the fetus and the presence or absence of fetal distress.

Emergency CS may dictate general anesthesia, which is the quickest method to deliver the fetus when time is critical, as in patient \#1. Commonly stated advantages of general anesthesia include the ability to control the airway, to maintain hypocarbia, and to control better hemodynamics. Disadvantages include the risks of unexpected difficult airway and aspiration, the need for careful selection of drugs and anesthetic agents, the need to maintain a smooth induction and emergence, and loss of the capacity to use the mother's level of consciousness as a neurologic monitor.

The use of regional technique in parturients with intracranial tumours is controversial. Injection of local anesthetics into the epidural space has been shown to increase ICP. ${ }^{18}$ However, spinal anesthesia using a 24gauge pencil-point spinal needle has been used successfully for CS in a patient with a brain tumour. ${ }^{1}$ There are also reports ${ }^{2,3}$ of the use of an epidural technique for management of labor and CS in patients with brain tumours. One of these patients had signs and symptoms of increased ICP at the time of epidural insertion. Inadverdent dural puncture may have disastrous consequences, as clinical deterioration and death have been reported. ${ }^{19}$

\section{Conclusion}

General anesthesia remains a safe and dependable technique in parturients with brain tumours who require cesarean section. Maternal hyperventilation, permitted by tracheal intubation, is useful to control raised intracranial pressure. Hemodynamic stability can be achieved to maintain cerebral perfusion. Whenever time permits, early consultations involving patient, obstetrician, anesthesiologist, and neurosurgeon are important for successful management.

\section{References}

1 Atanassoff PG, Wei BM. Spinal anaesthesia for Caesarean section in a patient with brain neoplasm. Can J Anaesth 1994; 41: 163-4.

2 Goroszeniuk T, Howard RS, Wright JT. The management of labor using continuous lumbar epidural analgesia in a patient with malignant cerebral tumour. Anaesthesia 1986; 41: 1128-9.

3 Finfer $S R_{.}$Management of labour and delivery in patients with intracranial neoplasm. Br J Anaesth 1991; 67: 784-7.

4 Statistics Canada 1998 estimate. Standardized according to Canadian Census, 1991. Personal Communication.

5 Roelvink NC, Kampjorst W, van Alphen, Roa BR. Pregnancy-related primary brain and spinal tumours. Arch Neurol 1987; 44: 209-15.

6 Pigott SE, Bogod DG, Rosen $M$, et al. Isoflurane with either $100 \%$ oxygen or $50 \%$ nitrous oxide in oxygen for caesarean section. Br J Anaesth 1990; 65: 325-9.

7 Lam Am, Mayberg TS, Eng CC, et al. Nitrous oxideisoflurane anaesthesia causes more cerebral vasodilation than equipotent dose of isoflurane in humans. Anesth Analg 1994; 78: 462-8.

8 Matta BF, Lam AM. Nitrous oxide increases cerebral blood flow velocity during pharmacologically induced EEG silence in humans. J Neurosurg Anaesthesiol 1995; 7: 89-93

9 Warren TW, Datta S, Ostheimer GW, Naulty JS, Wewiss $J B$, Morrison $J A$. Comparison of the maternal and neonatal effects of halothane, enflurane and isoflurane for cesarean delivery. Anesth Analg 1983; 62: 516-20.

10 Abboud TK, Zhu J, Richardsan M, Peres da Silva, E Donovan $M$. Desflurane: a new volatile anaesthetic for caesarean section. Maternal and neonatal effects. Acta Anaesthesiol Scand 1995; 39: 723-6.

11 Gambling DR, Sharma SK, White PF, Van Beveren $T$, Bala AS, Gouldson R. Use of sevoflurane during elective cesarean birth: a comparison with isoflurane and spinal anaesthesia. Anesth Analg 1995; 81: 90-5.

12 Newberg LA, Milde JH, Michenfelder JD. The cerebral metabolic effects of isoflurane at and above concentra- 
tions that suppress cortical electrical activity. Anesthesiology 1983; 59: 23-8.

13 Messick JM, Casement B, Sharborough FW, et al. Correlation of regional cerebral blood flow ( $\mathrm{rCBF}$ ) with EEG changes during isoflurane anesthesia for carotid endarterectomy: critical rCBF. Anesthesiology 1987; 66: 344-9.

14 Korula $G$, Farling $P$. Anaesthetic management for a combined caesarean section and posterior fossa cran iotomy. J Neurosurg Anaesthesiol 1998; 10: 30-3.

15 Bruns $P D$, Linder $R O$, Battaglia $F$, et al. The placental transfer of water from the fetus to mother following intravenous infusion of hypertonic mannitol to the maternal rabbit. Am J Obstet Gynecol 1963; $68:$ 160-7.

16 Bain $M D$, Copas Dk, Landon MJ, Stacey TE. In vivo permeability of the human placenta to inulin and mannitol. J Physiol (Lond) 1988; 399: 313-9.

17 Bensky AS, Kothadia JM, Covitz W. Cardiac effects of dexamethasone in very low birth weight infants.

Pediatrics 1996; 97: 818-21.

18 Hilt $H$, Gramm J, Link J. Changes in intracranial pressure associated with extradural anaesthesia. $\mathrm{Br}$ J Anaesth 1986; 58: 676-80.

19 Duffy GP. Lumbar puncture in the presence of raised intracranial pressure. BMJ 1969; 1: 407-9. 